\title{
ASPECTOS CONTROVERSIALES DE LA AUDIENCIA DE ACUSACIÓN
}

Controversial aspects of the criminal prosecution hearing

Álvaro Salgado González ${ }^{1}$

Andrés Paulo Cortina ${ }^{2}$

\section{RESUMEN}

Este artículo estudiará las problemáticas más significativas que se suscitan en la audiencia de acusación, como aquellas que surgen al adicionar hechos nuevos que no fueron enrostrados por la fiscalía en la audiencia de imputación de cargos. Ello constituye una violación al derecho de defensa del imputado porque se le está sorprendiendo con hechos de los cuales no tuvo la oportunidad de defenderse. Así, plantearemos una posible solución para convalidar tal situación sin el extremo de llegar a una nulidad. También se analizarán los errores más comunes en los que incurren los fiscales a la hora de plasmar los hechos jurídicamente relevantes, lo que es la hipótesis fáctica que encuadra el tipo penal. Por otra parte, se analizará el vacío normativo que tiene nuestro estatuto procesal penal respecto al retiro del escrito de acusación y finalmente se explicará por qué no es susceptible pedirse la nulidad del escrito de acusación.

Palabras clave: acusación, imputación, nulidad, hechos jurídicamente relevantes, defensa.

\section{ABSTRACT}

This article will study the most significant issues that arise in the hearing of accusation, such as those that arise from the addition of new facts that were not they coiled by the prosecution in the indictment hearing. This is a violation of the defendant's right of the accused because he is being surprised with facts that he did not have the opportunity to defend himself. Thus, we'll propose a possible solution to validate such a situation without the end of reaching a nullity. It will also analyze the most common mistakes made by prosecutors when capturing legally relevant facts, which

\footnotetext{
${ }^{1}$ Docente investigador de la Facultad de Derecho y ciencias Políticas de la Universidad de Cartagena, Director del Semillero Germinación Penal adscrito al Grupo Derechos humanos y Teoría Fundamental PHRONESIS, Docente de Pregrado y Postgrado del Programa de Derecho de la Universidad de Cartagena. ORCID ID: https://orcid.org/0000-0001-7619-3468 E-mail: alvarosalgadog@gmail.com

${ }^{2}$ Estudiante activo del Semillero Germinación Penal de la Facultad de Derecho y Ciencias Políticas de la Universidad de Cartagena.
} 
is the factual hypothesis that frames the criminal category. On the other hand, we'll analyze the normative gap that our criminal procedure statute has respect to the withdrawal of the indictment and finally we will explain why it is not possible to request the nullity of the indictment.

Keywords: Accusation, imputation, nullity, legally relevant facts, defense.

\section{INTRODUCCIÓN}

Primeramente, para abordar este punto es de vital importancia dejar por sentado que la audiencia de formulación de acusación es una de las más importantes en nuestro proceso penal, ya que demarca los linderos sobre los cuales ha de versar la discusión. Es tan importante que sin acusación no hay sentencia. Por este motivo, es obligación de la Fiscalía General de la Nación enrostrar unos determinados hechos, expresar que calificación jurídica le da a esos hechos, y, por último, determinar la plena identidad e individualización del futuro acusado.

Lo anterior puesto que la Corte Suprema de Justicia en Sala de Casación Penal ha afirmado que la congruencia consta de tres aristas (personal, fáctica y jurídica), pero esto no quiere decir que esa calificación primigenia sea absoluta porque en el juicio oral se ha facultado al juez para que readecúe la conducta en el tipo penal que considere pertinente, siempre y cuando se cumpla los requisitos dados por la jurisprudencia para tal efecto. En pocas palabras, la acusación terminaría siendo un acto formal y provisional, pero no se ahondará en esta oportunidad tal punto. Por otro lado, si producto de una ardua labor investigativa se obtienen elementos materiales probatorios, evidencia física e información legalmente obtenida que indican con probabilidad de verdad que la conducta típica existió y que el procesado es el autor o participe de la misma, se procede a presentar el escrito de acusación (Código de procedimiento penal, 2004) ${ }^{3}$.

En un segundo plano, se descubren los medios potencialmente probarios que la fiscalía hará valer en el gran juicio oral para demostrar la existencia de la conducta punible y la responsabilidad en cabeza del procesado. Lo antes dicho constituye la piedra angular del debido proceso probatorio, que no es otro que la búsqueda del elemento material probatorio, para, posteriormente, realizar su recopilación y embalaje, respetando la reglamentación sobre la materia. En un segundo momento el descubrimiento probatorio, seguido la solicitud y el decreto de los medios probatorios, y, por último, su práctica y valoración.

En un tercer plano, se da el reconocimiento de la víctima como interviniente especial para aportar, solicitar, controvertir las pruebas y demás facultades que tienen los sujetos procesales.

\footnotetext{
${ }^{3}$ Artículo 336. Presentación de la acusación: El fiscal presentará el escrito de acusación ante el juez competente para adelantar el juicio cuando de los elementos materiales probatorios, evidencia física o información legalmente obtenida, se pueda afirmar, con probabilidad de verdad, que la conducta delictiva existió y que el imputado es su autor o partícipe.
} 


\section{Principio de coherencia.}

Lo que respecta en esta oportunidad es analizar el principio de coherencia que introduce la honorable Corte Constitucional en el que se denota que al escrito de acusación no se le pueden adicionar hechos nuevos que en su oportunidad no fueron imputados por la fiscalía. Como es sabido en la audiencia de formulación de imputación también se habla de hechos jurídicamente relevantes, es decir que el ente investigador en una primera oportunidad endilgó unos hechos que en la audiencia de acusación no le es permitido modificar, puesto que violaría el principio de coherencia o de correlación de la imputación con la acusación. Así se refiere la Corte Interamericana de Derechos Humanos, en el asunto Fermín Ramírez vs. Guatemala:

La descripción material de la conducta imputada contiene los datos fácticos recogidos en la acusación, que constituyen la referencia indispensable para el ejercicio de la defensa del imputado y la consecuente consideración del juzgador en la sentencia. ...De ahí que el imputado tenga derecho a conocer, a través de una descripción clara, detallada y precisa, los hechos que se le imputan. La calificación jurídica de éstos puede ser modificada durante el proceso por el órgano acusador o por el juzgador, sin que ello atente contra el derecho de defensa, cuando se mantengan sin variación los hechos mismos y se observen las garantías procesales previstas en la ley para llevar a cabo la nueva calificación. El llamado "principio de coherencia o de correlación entre acusación y sentencia" implica que la sentencia puede versar únicamente sobre hechos o circunstancias contemplados en la acusación.

Es decir que la imputación vendría a ser, más que un simple acto de comunicación que la fiscalía hace al procesado, un condicionante factico de la acusación e indefectiblemente de la sentencia. Esta problemática solo se predica en el aspecto factico porque como es sabido el proceso penal es dinámico y variable, es decir, que en desarrollo del mismo la conducta se podría encuadrar en un tipo penal totalmente diverso al inicial.

Para ilustrar mejor los anteriores argumentos, se planteará la siguiente situación: Juan todas las mañanas suele salir a ejercitarse por la avenida Santander, a la altura de las murallas es abordado por dos sujetos con un arma de fuego. Estos le piden que le entregue sus pertenecias, Juan por su parte opone resistencia y los sujetos le propinan dos heridas con arma blanca a la altura del rostro, se llevan su celular y 300.000 mil pesos en efectivo. Los sujetos son capturados en la huida y son presentados ante un juez de control de garantías donde la fiscalía les imputa fácticamente que se apoderaron de una cosa mueble ajena, se trata de un celular marca iPhone S6 y 300.000 mil pesos en efectivo, pero en su narración de los hechos nunca se pronunció con respecto a las lesiones personales. En la audiencia de acusación, la fiscalía adiciona a sus pretensiones las lesiones personales y sumado a eso aporta un dictamen de medicina legal donde acredita las mismas. La pregunta es, ¿se estaría sorprendiendo a la defensa con hechos nuevos de los cuales no tuvo la oportunidad de preparar su defensa? Y, de ser así, ¿se estaría inmerso en una causal de nulidad? 
La respuesta es afirmativa con respecto a que se vulnera el derecho a la defensa porque de una $\mathrm{u}$ otra forma se están adicionando hechos nuevos que no fueron dados a conocer y de los cuales no se tuvo la oportunidad de preparar su contradicción, tanto es así, que el procesado no está obligado a soportar los errores de la fiscalía ni de la defensa. Por parte de la solicitud de nulidad no es víable porque se debe entender a la nulidad como aquella herramienta cuando se ha desquiciado ex abruptamente el proceso y no hay otro instrumento para enderezar sus derroteros, en ese entendido, la nulidad para el proceso penal es como aquella cicuta para Sócrates. En este caso, esa afectación se puede convalidar en la audiencia preparatoria al excluir o rechazar el dictamen de medicina legal donde se acreditan las lesiones personales por tornarse de impertinente, es decir, que tal dictamen no se refiere directa o indirectamente a acreditar los hechos jurídicamente relevantes. En pocas palabras, no se puede practicar una prueba que no intente convencer sobre un asunto tratado en el proceso, y en el caso planteado, fácticamente no existen las lesiones personales.

También el fiscal podría solicitar una nueva imputación por el delito que esta impune, en este caso las lesiones personales, y solicitar la unidad procesal por cumplirse los presupuestos consagrados para darse la conexidad y de esta forma juzgar ambos delitos en una misma cuerda procesal.

Pero hay que aclarar que existe un estrecho limite a la hora de aplicar este principio porque si la fiscalía en la audiencia de imputación de cargos habló fácticamente de las lesiones personales y jurídicamente no dijo en qué tipo penal se encuadraba, entonces no estamos inmersos en la situación anterior, porque si bien no fueron imputadas jurídicamente, si se habló en su momento de que existían las lesiones, entonces no es óbice para decir que se sorprendió a la defensa.

Bajo el mismo supuesto de hecho anteriormente mencionado, se puede dar la situación de que el fiscal no tiene a su disposición el dictamen de medicina legal donde se acreditan las lesiones y sumado a eso se encuentra ad portas de que se venza su oportunidad para descubrir los elementos materiales probatorios, en efecto, para que la conducta no quede impune se podría dar la posibilidad de acusar por las lesiones personales más benignas en virtud del principio de favorabilidad del que goza todo procesado, $y$, bajo nuestro criterio, no se estaría configurando ningún yerro procesal que afecte las garantías del derecho de defensa.

Hay que decir, de manera categórica, que entre más amplia y cuidadosa sea la imputación de cargos (claro está, sin ser ambigua) más amplio será el espacio de movilidad que tendrá la fiscalía en la audiencia de acusación y podrá de manera clara, concreta y precisa dar a conocer sus pretensiones sin margen de error alguno.

Ante esta situación hay que dejar por sentado que el principio de coherencia junto con el de congruencia no solo se predica de la imputación a la acusación, sino desde la imputación misma hasta 
la sentencia, ya que el proceso penal es una estructura en las que sus piezas no pueden estar de manera deshilvanada, porque se tendría un resultado totalmente adverso a lo que este persigue, que no es más que la justicia, la verdad, la reparación de los perjuicios causados producto del delito y la efectividad del derecho sustancial.

\section{Hechos jurídicamente relevantes.}

Suele toparse en los estrados judiciales con escritos de acusaciones donde simple y llanamente se reducen a transcribir las entrevistas de las víctimas, los informes de policía judicial, dictámenes de medicina legal, entre otros, dejando de lado la carga que le impone el legislador a los fiscales de delimitar los hechos jurídicamente relevantes, a fin de acotar y precisar sus pretensiones para un correcto ejercicio de la defensa y obtener una mayor eficiencia y celeridad de la administración de justicia.

La honorable Corte Suprema de Justicia en Sala de Casación Penal ( $\operatorname{Rad} \mathrm{n}^{\circ}$ 44599.-2017) afirma que "los hechos jurídicamente relevantes son los que corresponden al presupuesto factico previsto por el legislador en las respectivas normas penales". En pocas palabras, es la hipótesis fáctica que se encuadra en el tipo penal. Verbigracia, Juan con arma de fuego disparó y mató a Pedro, los anteriores hechos constituyen el posible delito de homicidio consagrado en el artículo 103 del código penal.

Surge la siguiente pregunta, ¿qué pasa si la fiscalía se reduce en los hechos jurídicamente relevantes a describir los medios de pruebas en lugar de poner de presente la hipótesis fáctica en la que ocurrieron los hechos? ¿De qué debe defenderse el acusado? O, más bien, la pregunta sería, ¿de qué se va a acusar al procesado?

"Que del informe de policía judicial FPJ narra que lo encontraron con una piedra en la mano y su esposa estaba llorando, entonces esta conducta se encuadra en el tipo penal de violencia intrafamiliar, o yo lo acuso de que María lo vio correr luego de la detonación de los disparos”...

Con lo anterior no se está diciendo que los indicios y los medios de pruebas resulten inútiles, por el contrario, se constituyen en pieza fundamental para conformar la teoría del caso del ente acusador, pero no pueden ser concebidos los anteriores como hechos jurídicamente relevantes y a la vez como medios potencialmente probatorios, así se refiere la Corte con respecto a este tópico:

Lo anterior sucede en eventos como los siguientes: (i) se relacionen de forma deshilvanada "hechos indicadores" y/o el contenido de los medios de prueba, pero no se estructura una hipótesis completa de hechos jurídicamente relevantes; (ii) la falta de claridad en la hipótesis de hechos jurídicamente relevantes propuesta por la Fiscalía, impide delimitar el tema de prue- 
ba; (iii) en la audiencia de acusación se le proporciona información al Juez, que sólo debería conocer en el juicio oral, con apego al debido proceso probatorio; (iv) las audiencias de imputación y acusación se extienden innecesariamente, y suelen tornarse farragosas; (v) la falta de claridad de la imputación y la acusación puede privar al procesado de la posibilidad de ejercer adecuadamente su defensa; (vi) las omisiones en la imputación o la acusación puede generar impunidad, como cuando se dejan de relacionar hechos jurídicamente relevantes a pesar de que los mismos pueden ser demostrados (elementos estructurales del tipo penal, circunstancias de mayor punibilidad, etcétera) (CSJ, sala de casación penal, sentencia SP 3168-44599, 2017).

En el diario devenir de los operados judiciales se encuentran esta serie de inconsistencias que parecieren no alterar en lo absoluto el proceso penal, pero resulta ser más importante de lo que se piensa porque la fiscalía al no poner de presentes de manera clara y precisa sus pretensiones, le será muy complicado presentar una teoría del caso que lleve al juez de turno más allá de toda duda razonable.

Entonces la pregunta del defensor ya no sería de qué me defiendo, sino ¿de qué acusan a mi cliente? De manera enfática y categórica se debe responder este interrogante de manera afirmativa, porque es obligación de la fiscalía dar a conocer de manera clara sus pretensiones y si no le es posible hacerlo, el juez no tiene otra opción que absolver ya que no se logró destruir la presunción de inocencia que se debe mantener incólume en todo momento.

Si nos trasladamos al procedimiento civil nos encontraremos con que el demandante debe expresar de manera clara y expresa los supuestos de hecho y pretensiones que pretende hacer valer, en todo caso si no cumple con esos requerimientos el juez no podrá condenar en constas al demandado y en su defecto proferirá una sentencia de carácter desestimatorio o inhibitorio.

En corolario de lo expuesto, es menester traer a colación el fallo de la CSJ 7 NOV. 2018 SP4792, que en una primera oportunidad el aquo absuelve al procesado porque el ente acusador no logró dar a conocer en debida forma los hechos jurídicamente relevantes y la violación del deber objetivo de cuidado. Posteriormente, fue apelada la sentencia y el tribunal revocó la decisión. En un último instante, el objeto de estudio llegó hasta la sala de casación penal de la corte, donde esa judicatura declaró la nulidad de una imputación de lesiones personales culposas, que a mi juicio deviene en una decisión judicial errada puesto que afirman que la imputación es más que un acto comunicacional, y concuerdo con ello, pero no con que si la imputación no es acorde con los lineamientos que prevé el estatuto procesal penal, es decir, no fue clara, sucinta y expuesta en lenguaje comprensivo, se demanda su nulidad. Aunado a lo anterior, se le pide al juez que tome una posición activa para evitar estos errores tan trascendentales al interior del proceso.

Por esta razón, reitero hasta la saciedad que el juez no puede estar haciendo el trabajo que le incumbe a las partes y más exactamente a la fiscalía, además no es viable como a bien le pareció a la 
corte, la nulidad de la imputación. Sí, es cierto que constituye más que un acto de comunicación, un acto de parte y un acto procesal, tanto así que sin imputación no hay proceso penal formalmente, pero el legislador le impone esa carga de dar a conocer de manera clara, precisa y en lenguaje comprensivo el supuesto factico que quiere hacer valer en el gran juicio oral y si no le es posible cumplir con esa carga la sanción debe ser la absolución, tal como lo hizo de manera acertada el juez de primera instancia.

\section{Nulidad del escrito de acusación.}

En el anterior código de procedimiento penal ley 600 de 2000, la Fiscalía General de la Nación cumplía funciones jurisdiccionales y, por ende, sus decisiones constituían resoluciones judiciales, tanto así, que a la acusación se le conocía con el nombre de resolución de acusación, y admitía los recursos de ley. Es decir, que sus actuaciones si tenían la potencialidad de vulnerar derechos y garantías fundamentales de los procesados.

En la actualidad, en vigencia del nuevo Código de Procedimiento Penal, ley 906 de 2004, se despoja y se cercena a la Fiscalía General de la Nación de tal facultad jurisdiccional, convirtiéndose el escrito de acusación en un acto de parte que no tiene la potencialidad de vulnerar derechos de los procesados.

En un proceso de roles adversos las partes se debaten para hacer valer sus pretensiones en el juicio oral, dado que el juez en la audiencia de acusación actúa como un mero árbitro, porque el control que le realiza a la acusación es meramente formal, es decir, solo se percata de que se cumplan los requisitos consagrados en el art.339 del C.P.P y de manera excepcional puede intervenir cuando se quebranten garantías fundamentales de las partes. Así se pronuncia la corte suprema de justicia (CSJ, sala de casación penal, proceso 41375, 2013) al decir que:

A los jueces de conocimiento, tender por el ejercicio imparcial de su función, abstenerse de complementar la labor de las partes y fijar las consecuencias sustanciales respectivas solo en el momento de adoptar la decisión que ponga fin a la actuación, ya que este es el momento procesal, -no antes- en el que ha de estar sometida a control la acusación de la Fiscalía, ya sea acogiéndola, desechándola $\mathrm{o}$, según lo ha precisado la jurisprudencia, morigerándola sin desbordar el marco fáctico de los hechos investigados. Igualmente, al interpretar las normas, el operador jurídico penal ha de propender, se insiste, por un ejercicio hermenéutico sopesado al tamiz de la sistemática del modelo acusatorio.

De lo antes dicho por la corte se debe afirmar que al juez de conocimiento le está vedado inmiscuirse en la acusación para entrar a relevar las funciones de los sujetos procesales porque de ser así, se estaría desnaturalizando la esencia del sistema penal acusatorio con tendencia adversarial y resultaría bastante penoso que el juez tenga que realizar el trabajo ya sea de la fiscalía o de la defensa. 
Retomando el tema sub judice, no es dable pedir la nulidad de un acto de parte, si bien es cierto, es un acto procesal que da impulso al proceso, no se puede decir que tiene la potencialidad de vulnerar derechos, como ya quedo claro en líneas anteriores. Además, no resulta adecuado pedir la nulidad de un acto incompleto, porque hasta ese momento lo que existe es un mero escrito que sólo tiene efectos para solicitar un juez competente o en su defecto evitar un posible vencimiento de términos. En el orden establecido en el código de procedimiento penal, luego de verificada la presencia de las partes, cuando el juez pregunta si existen causales de incompetencia, impedimentos o recusación y causales de nulidad, es donde se interpone la solicitud de nulidad no siendo aún verbalizada la acusación, ¿es posible que se nulite un acto que ni siquiera ha nacido a la vida jurídica?, de manera contundente hay que responderse este interrogante de manera negativa, porque la nulidad recae sobre actos que nacieron a la vida jurídica pero que por estar, ya sea en contra de una norma o carecer de algún requisito esencial para su validez, la ley demanda su invalidez. Es por esta razón es que se dice que es incompleto porque si bien el fiscal de turno puede modificar en todo o en parte el contenido de la acusación, de igual forma puede aclarar, corregir o adicionar.

En resumen de lo expuesto, la única opción que tiene el juez de conocimiento es hacer uso de sus poderes correccionales y rechazar esas solicitudes por ser infundadas e improcedentes (Código penal, 2004). Por otro lado, las causales de nulidad son taxativas tal como lo deja ver los artículos 456, y subsiguientes del C.P.P.

\section{Retiro del escrito de acusación}

Este suele ser uno de los puntos más críticos de nuestro sistema procesal penal, sin embargo de ello se habla poco. La ley 906 de 2004 no se refiere a este tópico, es por eso que queda a la libre interpretación de los operadores judiciales y de esta forma hace más propicie la comisión de yerros a la hora de toparse de frente con casos de tal índole.

Como se dijo anteriormente, además de ser la acusación un acto de parte, es un acto complejo que se agota en dos instantes, la presentación de escrito de acusación y su verbalización en audiencia. Por esta razón, es acertado decir que el fiscal puede retirar su escrito de acusación antes de ser verbalizado porque es allí donde toma impulso procesal, así lo deja ver la jurisprudencia de nuestra Corte Suprema de Justicia (CSP AP, 21 de mar. 2012, rad. 38.256):

Si el fiscal es el "dueño de la acusación” y al momento de radicar el escrito que la contenga lo que hace es una manifestación expresa de sus pretensiones ante el juez de conocimiento, nada impide que antes de que se haga efectiva la formulación en la audiencia respectiva pueda retirar su escrito, esto es, los cargos, en tanto en esa instancia se está ante un acto de parte, que aún no ha impulsado actividad jurisdiccional y, como acto de parte, bien puede desistir del mismo. 
"Ese retiro del escrito de acusación no exige decisión judicial (el asunto no entró en la órbita de la función del juez).

Por otra parte, hay que dejar sentado que el retiro del escrito de acusación no da por terminado el proceso penal, puesto que se mantiene intacta una imputación de cargos y la vía correcta para finiquitar la actuación con efectos de cosa juzgada, no es otra que la preclusión o en su defecto el principio de oportunidad. De lo anterior, hay que decir que esta postura no parece ser del todo pacifica porque hay doctrinantes incluso hasta operadores judiciales, que afirman que no se puede solicitar la preclusión luego de presentado el escrito de acusación, siendo esto, bajo nuestra óptica, totalmente equivocado porque como se ha reiterado en múltiples ocasiones la acusación es un acto complejo que no se entiende agotado con la sola presentación del escrito.

Así las cosas, es menester aterrizar en este punto porque al retirar el escrito de acusación y al no poder solicitarse la preclusión, porque se tiene la convicción errada de que se ha realizado la acusación, se estaría inmerso en una vía de hecho no regulada por nuestro estatuto procesal penal, pensaríamos en un dilema, ni se ejerce la acción penal ni se renuncia a la misma, haciendo de esta forma que el procesado recurra a vías constitucionales como el habeas corpus cuando se encuentre privado de su libertad.

\section{Conclusiones}

Cabe concluir que la audiencia de acusación constituye pieza fundamental del sistema penal acusatorio, es decir, demarca los derroteros sobre los cuales ha de truncarse la pugna, así pues no puede existir discusión fuera de la misma. Además de demarcar los derroteros sobre los cuales ha de versar la discusión tanto fáctica como jurídica, aunque como ya se dijo en el aspecto jurídico puede ser recalificada la conducta siempre que se den una serie de requisitos dados por la jurisprudencia.

Hay que dejar claro, que no se pueden agregar a la acusación hechos que no fueron imputados en su oportunidad y de serlo así se estaría vulnerado el derecho de defensa que reviste al procesado, pero lo anterior no es óbice para solicitar la invalidación de lo actuado porque en la audiencia preparatoria se puede convalidar tal defecto.

Con respecto a los hechos jurídicamente relevantes como se ha reiterado hasta la saciedad a lo largo de este escrito, se convierten en pieza fundamental para ejercer el derecho de defensa y en caso que no se logre cumplir con esta carga la salida no es otra, que la absolución.

En un sistema procesal con tendencia acusatoria como el nuestro, los retos y exigencias cada día suelen ser mayores para los jueces, abogados y fiscales que en los estrados judiciales realizan roles totalmente adversos. Pero no por esta razón quiere decir que no se complementen, pues 
sobre sus hombros recae el peso de la administración de justicia y todos constituyen un eslabón para alcanzar ese tan anhelado ideal de justicia.

\section{REFERENCIAS BIBLIOGRÁFICAS}

Corte IDH, Caso Fermín Ramírez vs Guatemala, (Excepciones Preliminares), Sentencia de 20 de junio de 2005, Serie C No. 126, párr. 67.

Corte Suprema de Justicia, Sala de Casación Penal. Sentencia SP 3168- 44599, M.P. Patricia Salázar Cuellar; 8 de marzo de 2017.

Corte Suprema de Justicia, Sala de Casación Penal. Sentencia SP 4792- 52507, M.P. Patricia Salazar Cuellar; 7 de noviembre de 2018.

Corte Suprema de Justicia, Sala de Casación Penal. Sentencia 4137, M.P. José Luis Barceló Camacho; 14 de agosto de 2013.

Corte Suprema de Justicia, Sala de Casación Penal. Auto interlocutorio 38256, M.P. José Luis Barceló Camacho; 21 de marzo de 2012.

Código de Procedimiento Penal [CPP]. Ley 906 de 2004. 31 de agosto de 2004 (Colombia).

Código Penal Colombiano [CP]. Ley 906 de 2004. 31 de agosto de 2004 (Colombia). 